\title{
Production, characterization and mechanical properties of Solid form geopolymeric binder- via mechanochemical route using class-F fly ash.
}

SHAILESH KUSHWAH ( $\nabla$ shail.kush200890@gmail.com )

Academy of Scientific and Innovative Research

Manish Mudgal

AMPRI: Advanced Materials and Processes Research Institute CSIR

Ramesh Kumar Chouhan

AMPRI: Advanced Materials and Processes Research Institute CSIR

Avanish Kumar Srivastava

AMPRI: Advanced Materials and Processes Research Institute CSIR

\section{Research Article}

Keywords: mechanochemical, solid form geopolymer, split tensile strength

Posted Date: February 26th, 2021

DOI: https://doi.org/10.21203/rs.3.rs-236813/v1

License: (c) (i) This work is licensed under a Creative Commons Attribution 4.0 International License.

Read Full License 


\section{Abstract}

Here, we developed Solid form geopolymeric binder, the reaction between aluminosilicate material and dry chemicals i.e. fly ash with sodium hydroxide and sodium metasilicate by ball milling for $6 \mathrm{hrs}$. to make in solid form.. Mechanochemical ball milling of raw material causes a solid-state reaction between raw materials and form solid form geopolymeric precursor which requires the addition of water to make Solid form geopolymeric binder. This geopolymer has been characterized by different characterizing techniques, such as XRD, FTIR, FESEM, and EDAX, and evaluated for compressive, flexure, and split tensile strength. In our results, we had achieved a compressive strength of $55.4 \mathrm{MPa}$, flexure strength of $5.38 \mathrm{MPa}$, and split tensile strength of $3.9 \mathrm{MPa}$ after 28 days of testing. Solid form geopolymers have overcome the handling and hazards difficulties, which is associated with the conventional route. So now it is possible to use Solid form geopolymeric binder as general building construction and in-situ application for construction industry, which were limited to precast construction work by conventional geopolymer route.

\section{Full Text}

Due to technical limitations, full-text HTML conversion of this manuscript could not be completed. However, the latest manuscript can be downloaded and accessed as a PDF.

\section{Figures}

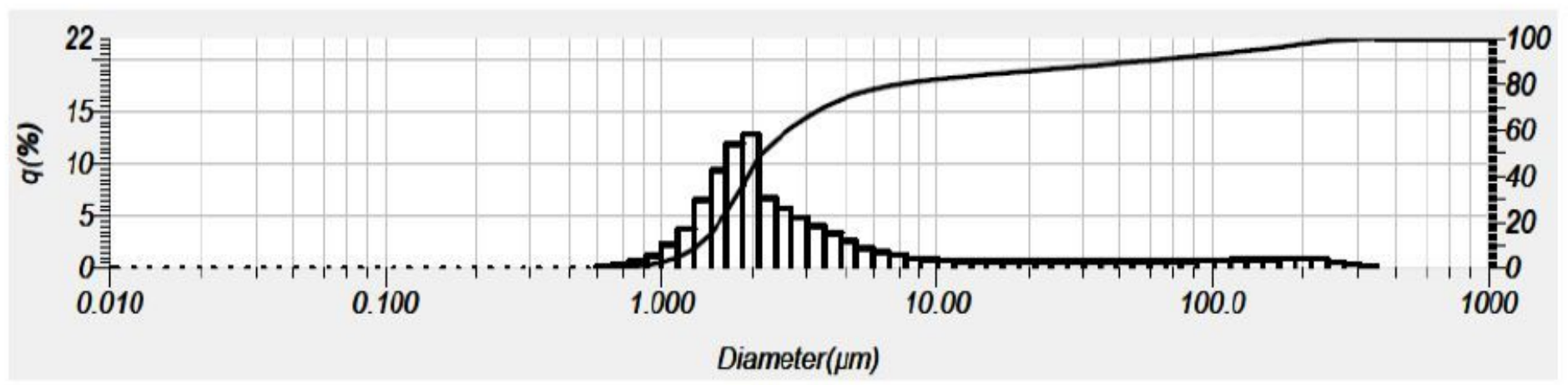

Figure 1

Particle size distribution of fly ash 


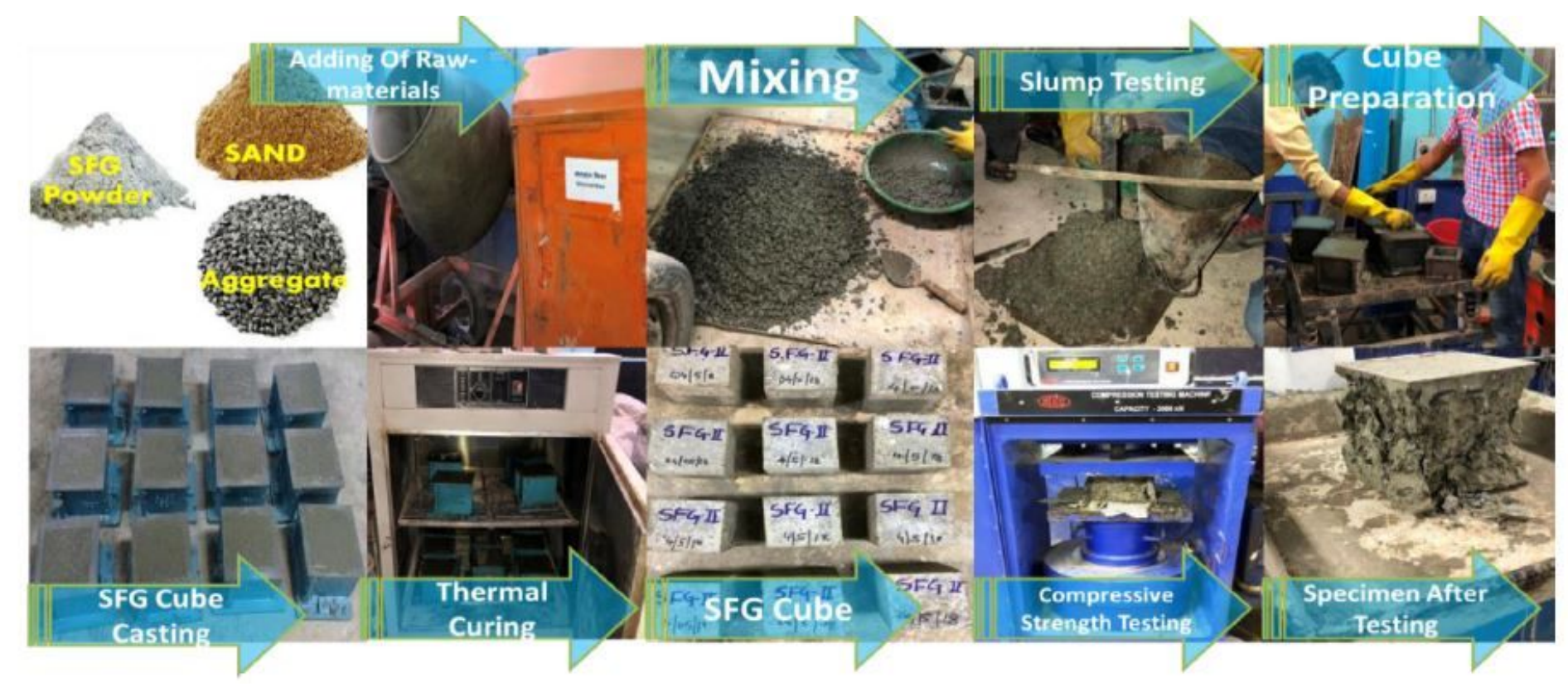

Figure 2

showing the process for making solid form geopolymer concrete

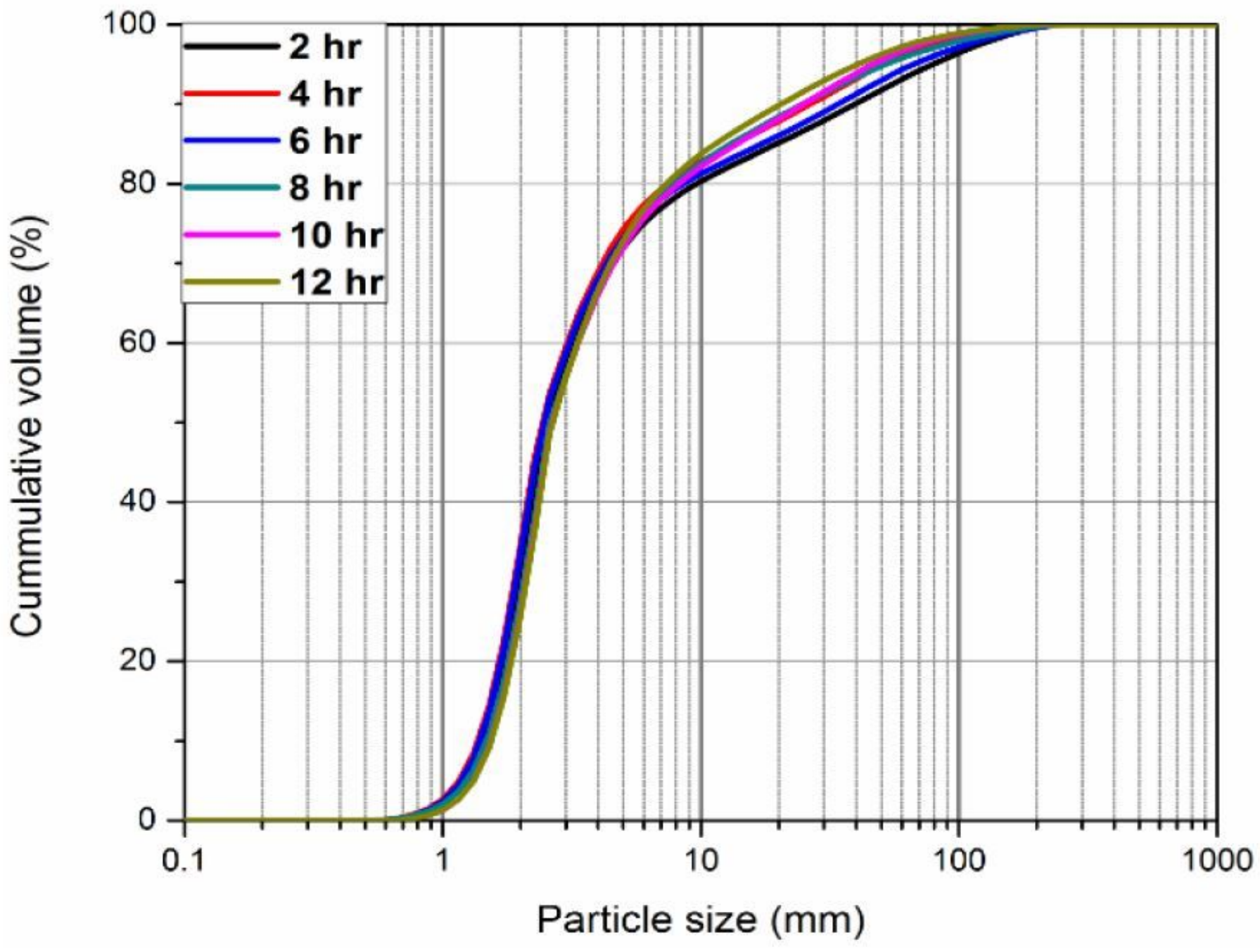


Figure 3

Particle size distribution of solid form geopolymeric precursor (powder).

(a)

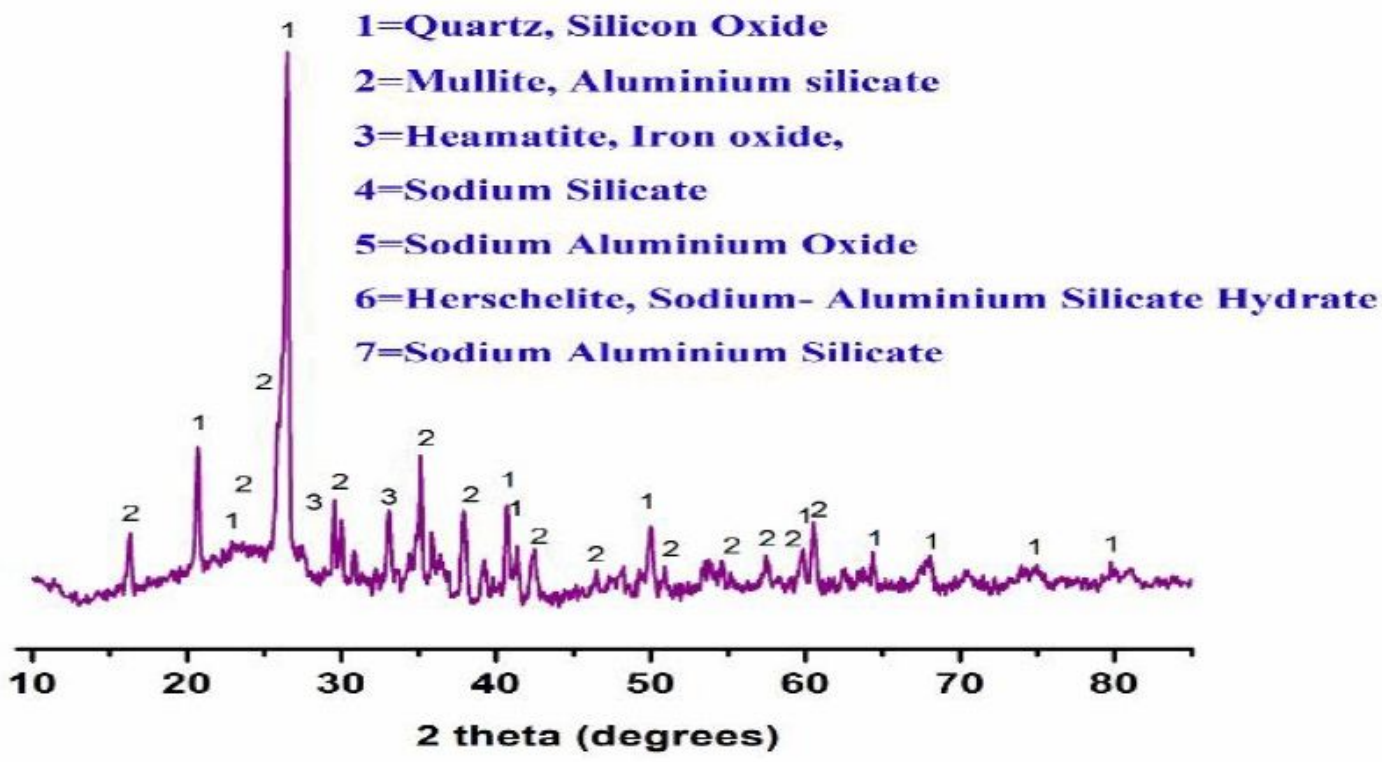

(b)

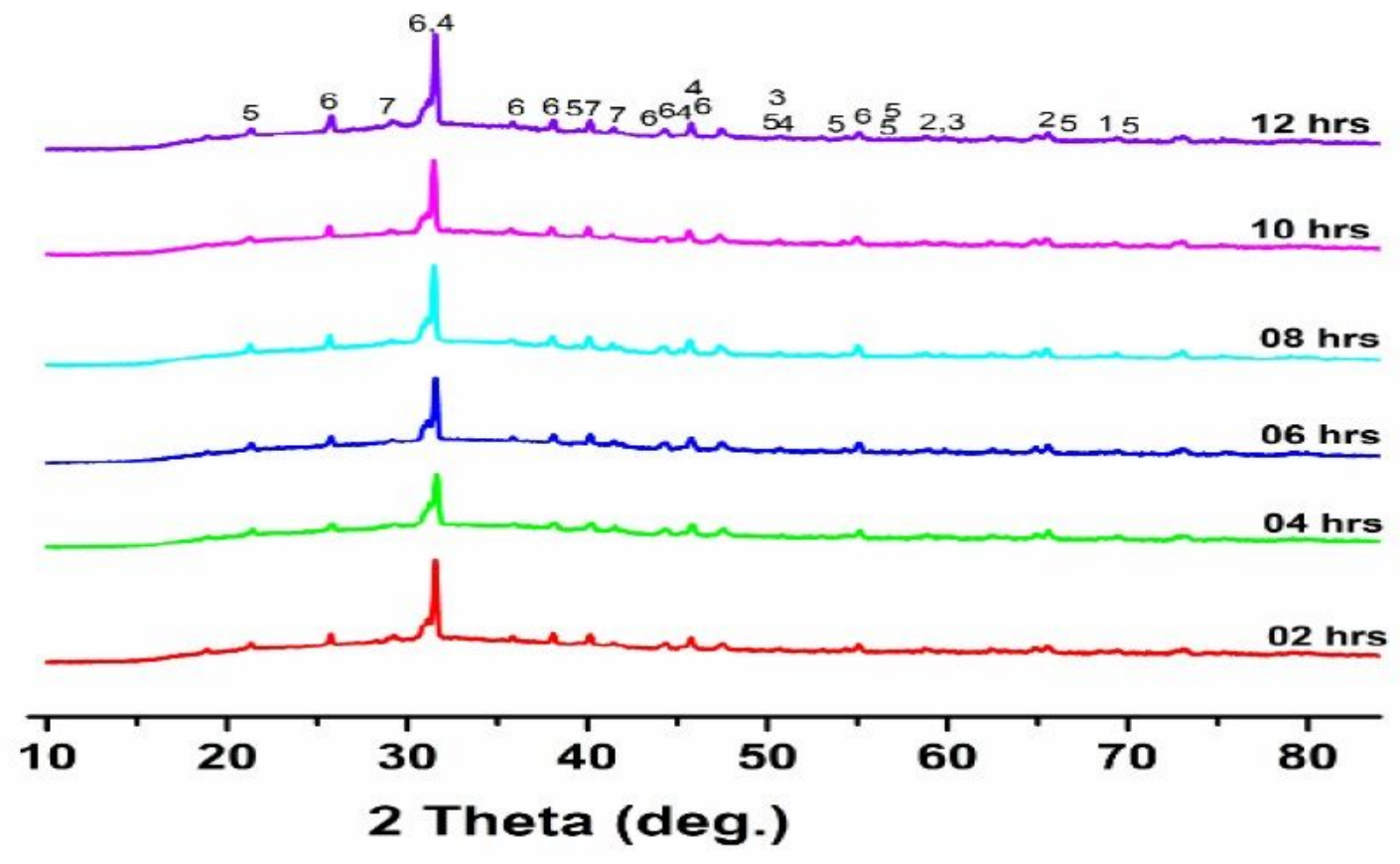

Figure 4

XRD patterns of (a) Class $\mathrm{F}$ fly ash (b) Solid form geopolymeric binder. 
(a)

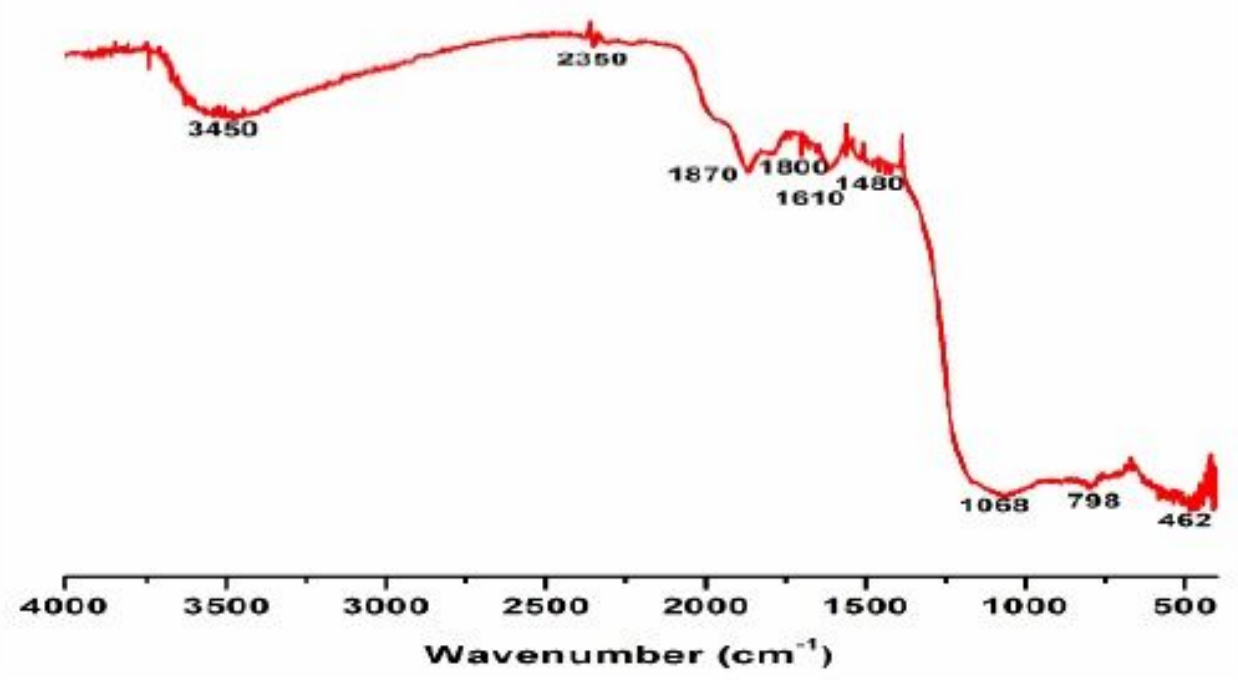

b

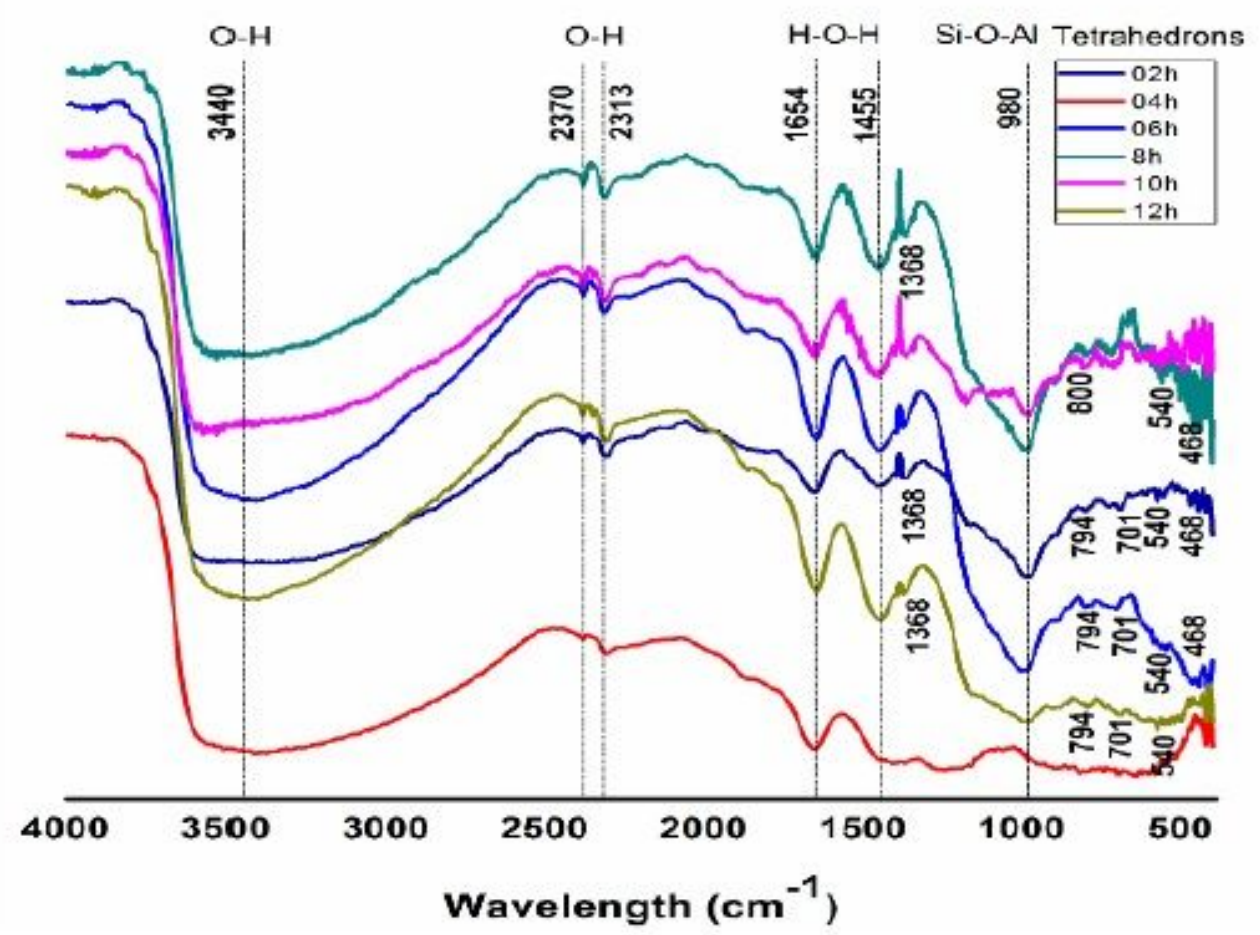

Figure 5

FTIR spectral bands of (a) Raw fly ash, (b) Solid form geopolymer binder 


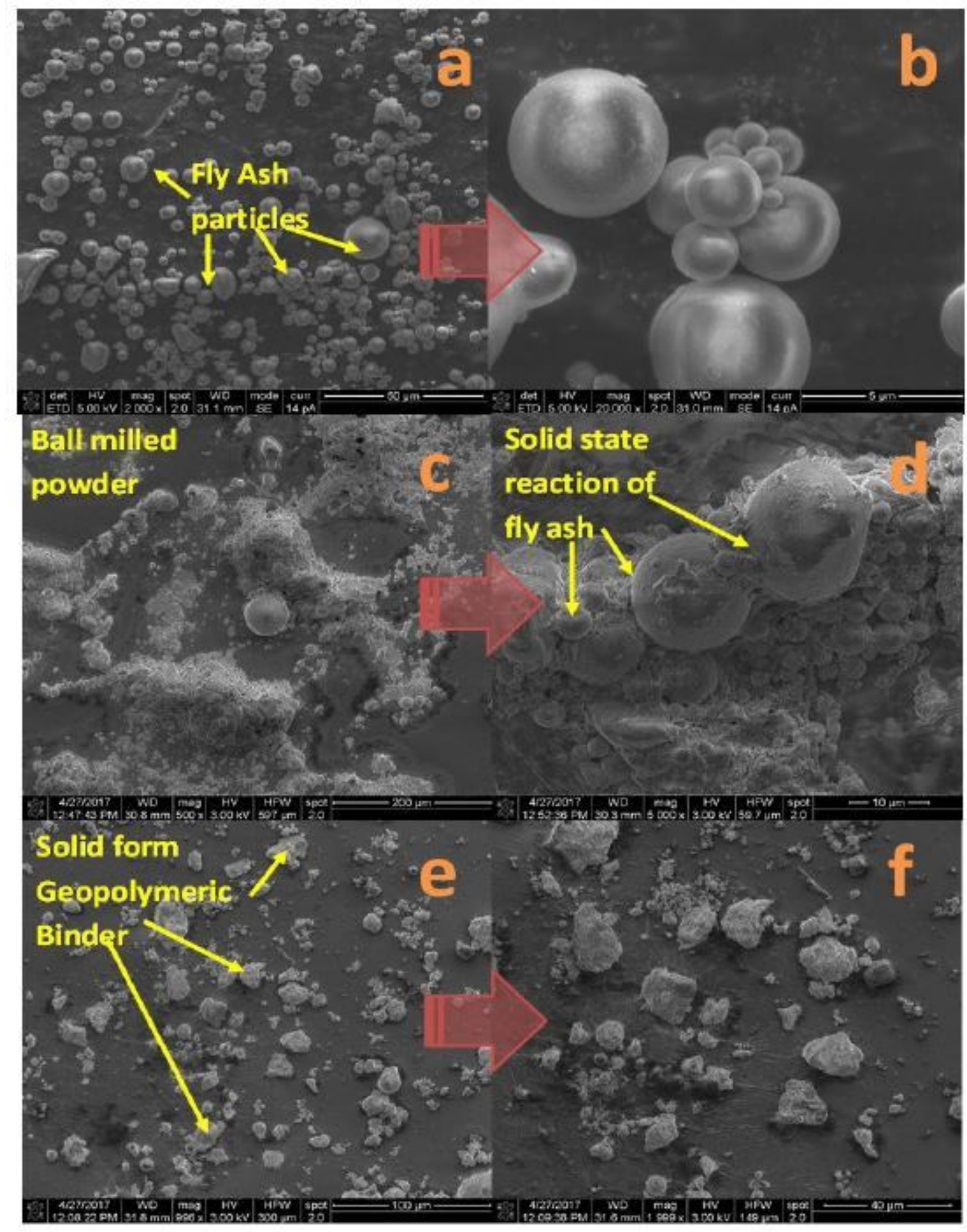

Figure 6

FESEM morphology of (a) Raw fly ash particle (b) Fly ash micro-sphere (c) Solid form geopolymeric precursor (d) Solid-state reaction between fly ash and alkali (e) Developed solid form geopolymeric binder 

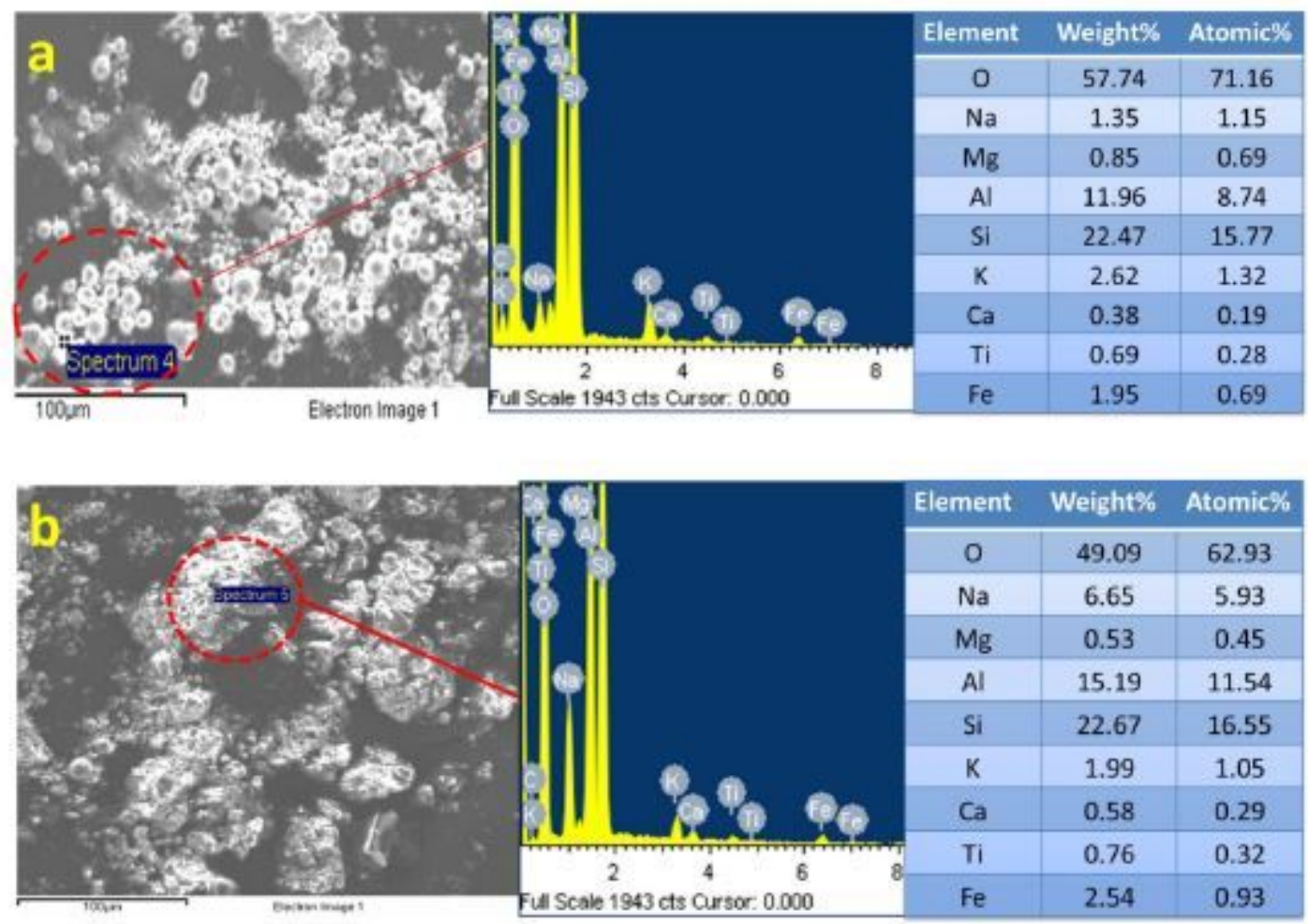

Figure 7

FESEM-EDX spectrum of (a) Raw fly ash (b) Solid form geopolymeric binder with elemental composition.

\section{Average Compressive Strength (MPa) of SFG Concrete}

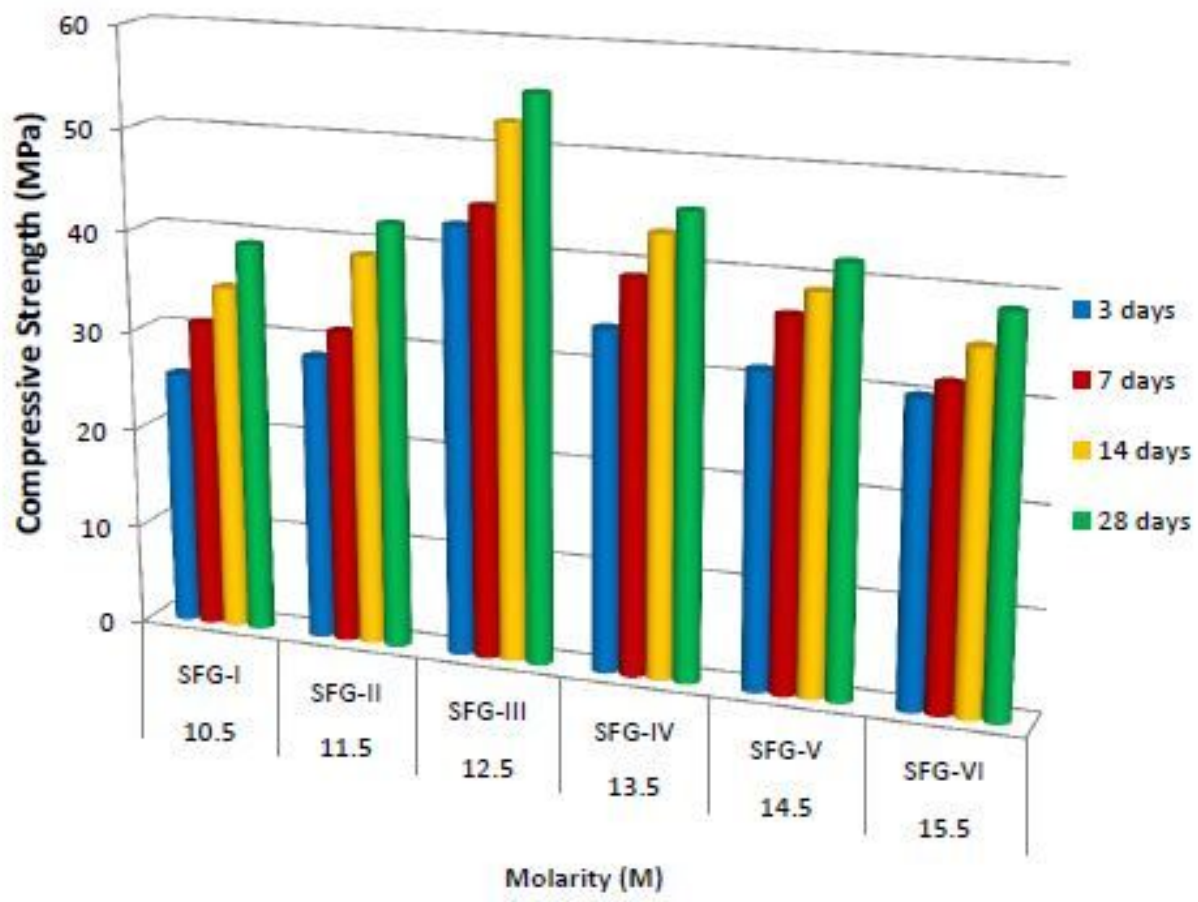


Figure 8

Variation in compressive strength of Solid form geopolymer concrete.

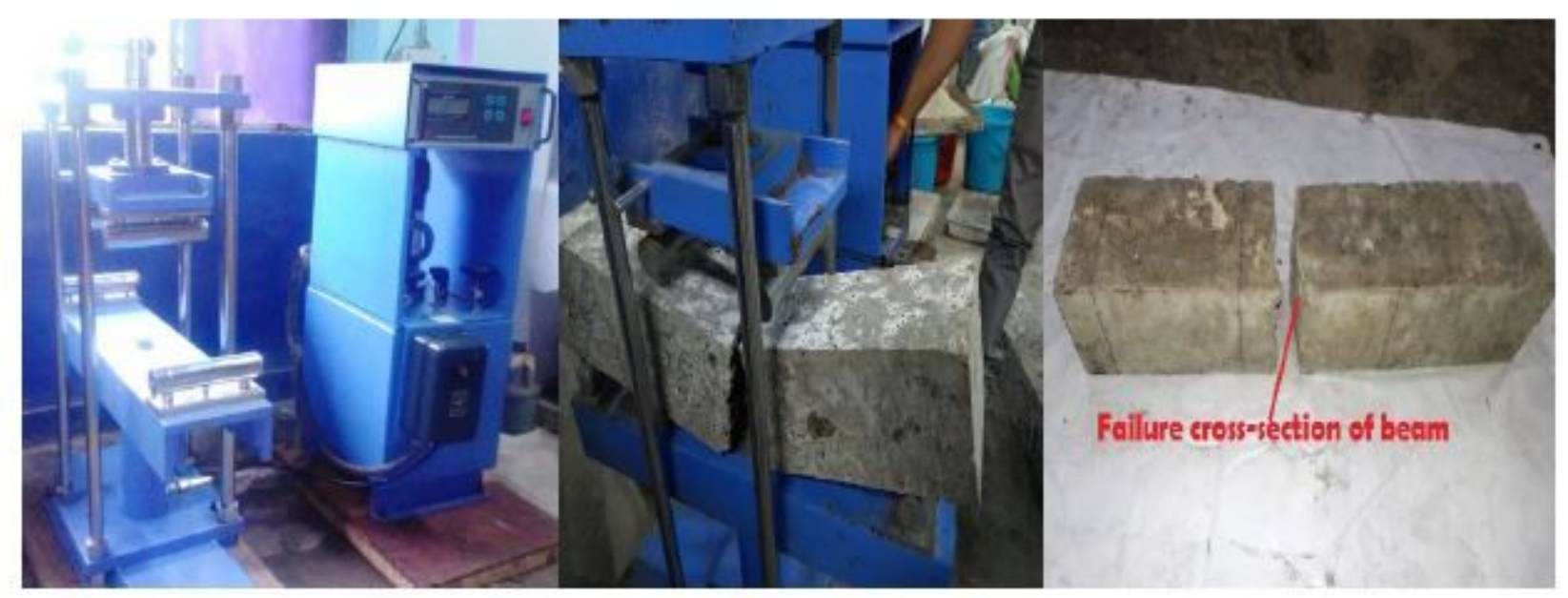

\section{Figure 9}

Flexure tensile strength testing of Solid form geopolymer concrete.

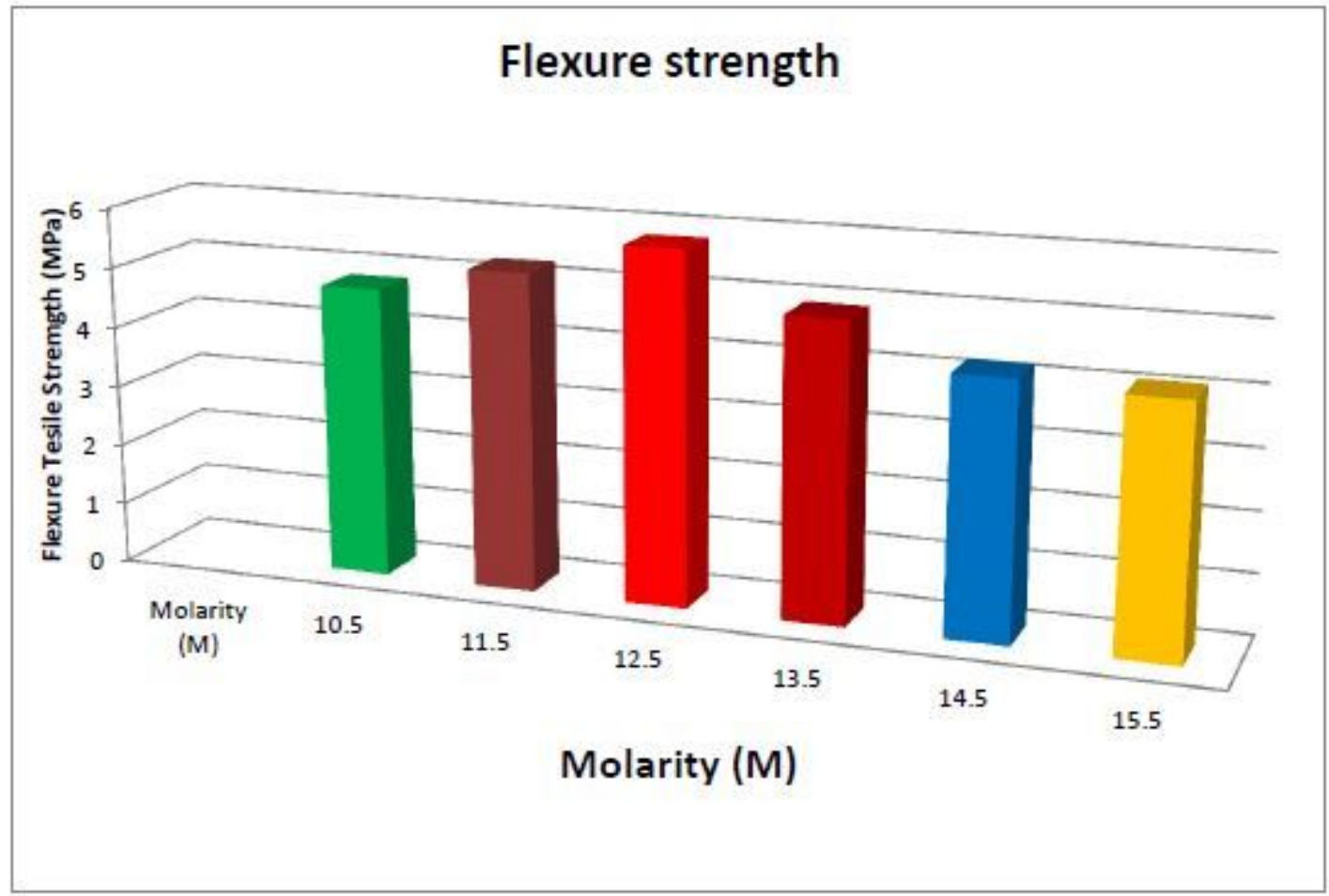

Figure 10

Variation in Flexure tensile strength of Solid form geopolymer concrete. 


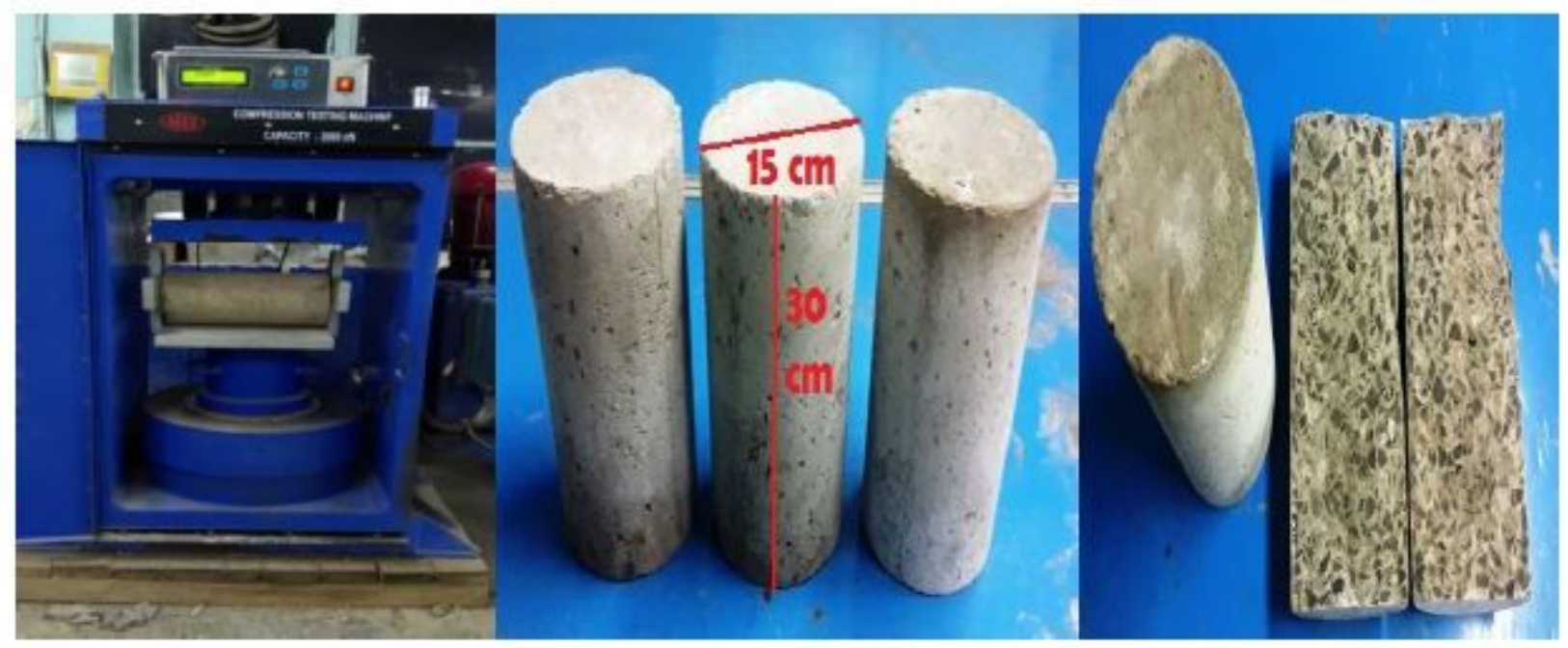

Figure 11

Split tensile strength testing of Solid form geopolymer cylindrical concrete block.

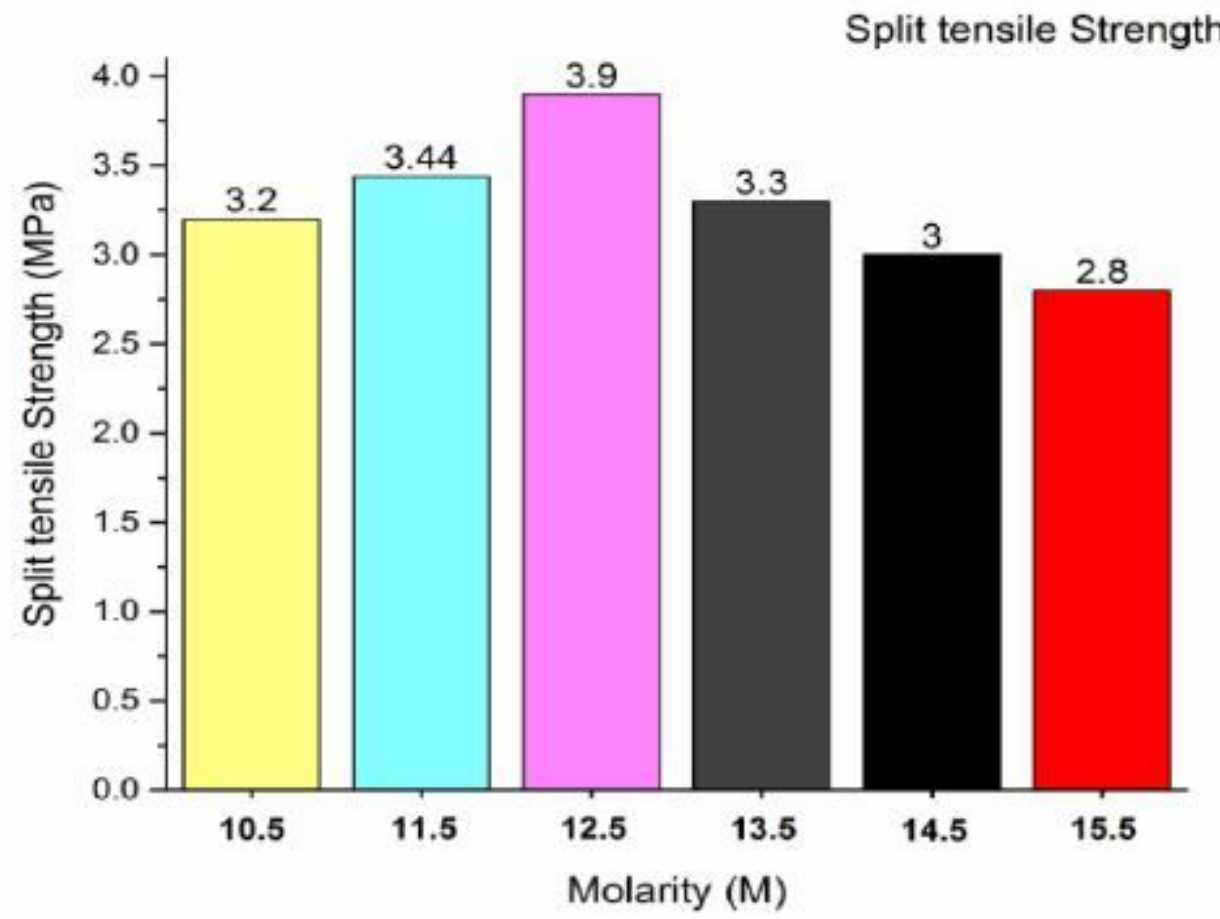

Figure 12

Split tensile strength of Solid form geopolymer concrete.

\section{Supplementary Files}

This is a list of supplementary files associated with this preprint. Click to download.

- Coverletter.pdf 